Corresponding Author:

M I Kartashov

maki505@rambler.ru

Received: 25 October 2019

Accepted: 15 November 2019

Published: 25 November 2019

Publishing services provided by Knowledge E

(c) M I Kartashov et al. This article is distributed under the terms of the

Attribution License, which

permits unrestricted use and

redistribution provided that the

original author and source are credited.

Selection and Peer-review under the responsibility of the AgroSMART 2019 Conference Committee.

\section{Co-application of Difenoconazole with Thymol Results in Suppression of a Parastagonospora Nodorum Mutant Strain Resistant to this Triazole}

\author{
M I| Kartashov', L A Shcherbakova ${ }^{2}$, N V Statsyuk ${ }^{3}$, and V G Dzhavakhiya ${ }^{1}$ \\ ${ }^{1}$ Department of Molecular Biology, All-Russian Research Institute of Phytopathology, Bolshie \\ Vyazemy, Russia \\ ${ }^{2}$ Laboratory of Plant Pathophysiology, All-Russian Research Institute of Phytopathology, Bolshie \\ Vyazemy, Russia \\ ${ }^{3}$ Department of Potato \& Vegetable Diseases, All-Russian Research Institute of Phytopathology, \\ Bolshie Vyazemy, Russia
}

\section{Abstract}

Results of in vitro study of thymol, a natural chemosensitizer, as a potential agent for overcoming of difenoconazole resistance of Parastagonospora nodorum causing glume and leaf blotch of wheat are first reported. The level of difenoconazole resistance of a natural mutant PNm1 strain with low sensitivity to the Dividend fungicide (a.i. difenoconazole) was determined by cultivation of this isolate on potato dextrose agar in the presence of the fungicide at sub-lethal and lethal (in relation to the initial fungicide-sensitive strain) concentrations. A principal possibility of the thymol use to overcome resistance of $P$. nodorum to DMI (demethylation inhibitors) fungicides is shown. Co-application of this compound with Dividend SC, 3 \% resulted in significant reduction of resistance of the mutant strain and enhancement of its sensitivity to difenoconazole up to the level corresponding to the initial non-resistant isolate.

Keywords: resistance, fungicides, chemosensitization, Parastagonospora nodorum, wheat, difenoconazole, thymol

\section{Introduction}

Agriculture is crucial for the economic growth and improvement of the life quality and well-being of people. Agricultural products make no less than one third of a global gross production. One of the main conditions to provide a steadily high yield is a successful control of plant pathogens. Unfortunately, excessive use of fungicides typical for intensive crop production results in contamination of food and environment with pesticide residues, significant reduction of biodiversity caused by suppression of both pathogenic and beneficial mycoflora, and also development of fungicide resistance 
population resulting in significant problems in a crop protection. The proper control of such strains requires multiple applications of fungicides at higher concentrations, since concentrations recommended for use in agricultural practice become inefficient, rendering short-lived, and sometimes economically unprofitable, antifungal effect [1].

Therefore, approaches aimed at the reduction of the effective dosages of commercial fungicides in order to reduce their toxic impact on the environment, are of great relevance. Such a reduction can be achieved by co-application of a fungicide with certain natural compounds at concentrations, when both fungicide and such compound, taken alone, provide no or marginal fungitoxic effect. Such strategy was called chemosensitization [2].

Our studies within the framework of a chemosensitization strategy are focused mainly on the search for natural compounds, which specifically target the stress-response systems of plant pathogens to enhance their sensitivity to agricultural fungicides. Combination of some commercial fungicides with certain phenolic acids or benzo analogues targeting cellular oxidative systems involved into a stress response has been reported to improve antifungal activity of these fungicides against pathogenic yeasts and filamentous fungi causing invasive mycoses in humans [3--5]. Based on these findings and a preliminary screening of compounds with a chemosensitizing potential, we selected several natural and synthetic compounds as putative chemosensitizers and tested them in combination with some azole- or strobilurin-based fungicides commonly used in agriculture, against several harmful plant pathogenic fungi [6]. This study demonstrated a potential for the use of such approach against Stagonospora nodorum (currently Parastagonospora nodorum), a fungus causing wheat glume and leaf blotch and having a significant economic importance in both nationaland global scale [7--10]. We showed that the antifungal activity of a difenoconazole-based Dividend fungicide towards $P$. nodorum significantly increased in the case of its in vitro co-application with nonfungitoxic concentrations of thymol, a plant secondary metabolite [6], which commercial preparations are available and widely used in medicine.

Thymol, a monoterpene phenol derivative of cymene (natural aromatic compound), is produced by various Thymus species [11] including culinary thyme (T. vulgaris), as well as some other herbs; it is contained in essential oils of these plants [12]. This compound is considered to destruct integrity of fungal cell membranes via reduction of the ergosterol content. When this natural product (taken at non-fungicidal concentrations) was combined with some antimycotic drugs, a synergistic increase in their pharmaceutical activity against human pathogens was observed [2]. 
The above considerations and our previous findings [6] became the starting point for this study aimed to investigate the potential of a thymol use as a biogenic chemosensitizing agent to overcome the resistance of $P$. nodorum to difenoconazole.

\section{Methods and Materials}

Thymol (2-isopropyl-5-methylphenol, CAS 89-83-8) was purchased from Sigma-Aldrich (now Merck, Germany). Difenoconazole (CAS 119446-68-3) was used in the form of a Dividend SC fungicide (3\%) produced by Syngenta.

Wheat grain samples artificially inoculated with $P$. nodorum isolates (36 in total) collected in different regions of Russia were provided by the infection nursery of the Central region of Russia located at the experimental field of the All-Russian Research Institute of Phytopathology (Moscow region). Each isolate was propagated by a solidphase cultivation on a grain substrate [13] to obtain spore suspensions for the further inoculation of potato-dextrose agar (PDA). Mycelium from the surface of colonies grown on PDA was used as an inoculum for the further evaluation of the pathogen sensitivity to the Dividend fungicide. To induce spore formation, the initial isolate and resistant mutant were exposed to UV irradiation [14].

To study the sensitivity of isolates to the fungicide, they were grown in Petri plates on PDA supplemented with different concentrations of difenoconazole ranging from 0.002 to $5.0 \mu \mathrm{g} / \mathrm{ml}$. In co-application experiments involving $P$. nodorum sensitizing with thymol, thymol was added to a final concentration of $10 \mu \mathrm{g} / \mathrm{ml}$, which was previously found to enhance the pathogen sensitivity to Dividend [6]. Prior to being poured into PDA, thymol or the fungicide were dissolved in a minimal volume of $10 \%$ DMSO, diluted with distilled water and sterilized by filtration through a $0.22-\mu \mathrm{m}$ Millipore membrane. Petri plates with PDA media containing difenoconazole or difenoconazole plus thymol were then inoculated by placing small fragments of a fungal mycelium onto the center of each plate and incubated in the dark at $25^{\circ} \mathrm{C}$ for different time periods followed by a colony diameter measurement. Control cultures were grown under the same conditions on PDA without addition of difenoconazole and thymol. Growth inhibition level was determined as a percentage of diminished growth of the tested isolates based on average diameter values, as compared to the control. To reveal synergism between thymol and difenoconazole, which suggests the pathogen sensitization to the fungicide, a Limpel's criterion was calculated using the following formula [15]:

$$
E_{e}=X+Y-(X Y / 100),
$$


where $E_{e}$ is an expected summary growth inhibition, $X$ and $Y$ are the growth suppression values (\%) obtained when each compound (fungicide and thymol) was used alone. Chemosensitizing effect was considered if the observed growth-inhibiting effect $\left(E_{r}\right)$ of difenoconazole co-applied with thymol exceeded the $E_{e}$ value calculated using the above formula

The experiments were arranged in three replications for each concentration of Dividend and/or thymol used. The statistical treatment of data was carried out using a STATISTICA 6.0 software (StatSoft Inc.). The means, standard errors or standard deviations were calculated for each variant, and then significant difference $(p \leq 0.05)$ between the mean values of the tested and control variants, as well as between different treatments were determined using a t-test for independent variables.

\section{Results}

In the course of the study we found that difenoconazole concentrations within the range of $0.002--0.04 \mu \mathrm{g} / \mathrm{ml}$ did not provide any statistically significant inhibiting effect on the growth of $P$. nodorum. At the same time, increase of its concentration to $0.05 \mu \mathrm{g} / \mathrm{ml}$ resulted in the suppression of the growth of 30 fungal isolates by $60--75 \%$ comparing to the control, while the growth of other 6 isolates did not exceed $10 \%$ of the control (all measurements were carried out 8 days after inoculation). Thus, all tested $P$. nodorum isolates from Russia were sensitive to difenoconazole. However, in the case of the isolate PN-18 collected in the Moscow region, one of its colonies grown at the sublethal difenoconazole concentration $(0.05 \mu \mathrm{g} / \mathrm{ml})$ formed a sector, which grew more intensively than other parts of this colony. Microscopic investigation of conidia collected from this sector showed their morphological identity with P. nodorum conidia (Fig. 1).
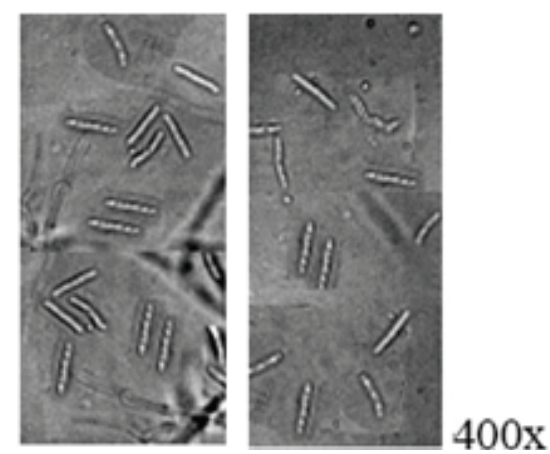

Figure 1: Spores of natural difenoconazole-sensitive Parastagonospora nodorum isolate PN-18 (left) and its difenoconazole-resistant mutant strain PNm1 (right).

Mycelium collected from the peripheral part of this sector, was used for inoculation of Petri plates with PDA containing $0.05 \mu \mathrm{g} / \mathrm{ml}$ of difenoconazole. We found that the 
suppression of the obtained strain (PNm1) with the fungicide was almost twice lower than that of the initial PN-18 (Fig. 2, 3).

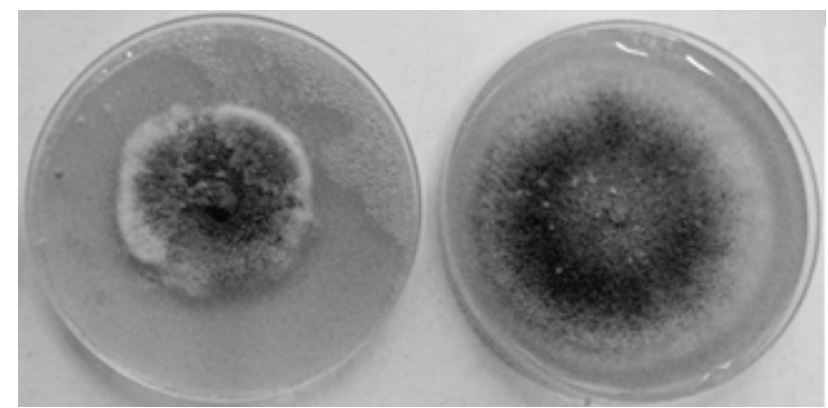

Figure 2: Colonies of difenoconazole-sensitive PN-18 isolate (left) and resistant PNm1 strain (right) of Parastagonospora. nodorum grown on potato dextrose agar supplemented with a difenoconazole-based Dividend fungicide $(0.05 \mu \mathrm{g} / \mathrm{ml}$ of difenoconazole).

The study of a difenoconazole resistance level of the second generation of the PNm1 strain performed by its cultivation in the presence of lethal and sub-lethal (for the initial isolate) concentrations of difenoconazole varying within the range of $0.05-1.5 \mu \mathrm{g} / \mathrm{ml}$ ) showed that the selected PNm1 colonies were characterized by a larger diameter than those of the initial isolate (Fig. 4).

To confirm that difenoconazole resistance of the PNm1 strain resulted from a mutation, this isolate within three weeks was twice consecutively re-inoculated onto a difenoconazole-free PDA. Then the isolate was cultivated on PDA supplemented with seven different difenoconazole concentration within the range of $0.05--5 \mu \mathrm{g} / \mathrm{ml}$. In parallel, a control (difenoconazole-sensitive) isolate was grown at the same concentrations of the fungicide.

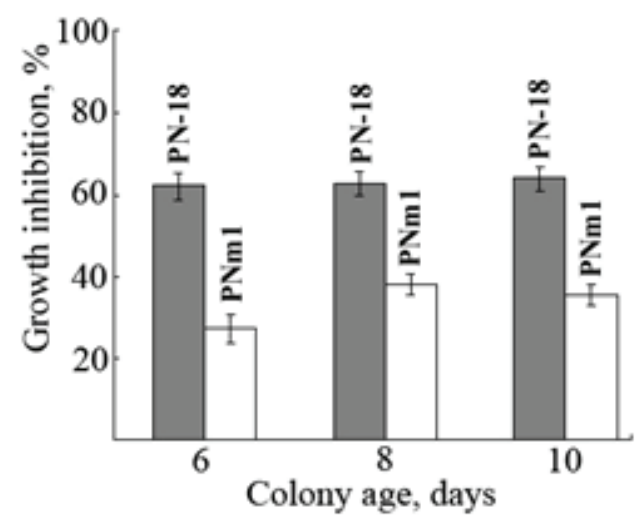

Figure 3: Colony growth inhibition of Parastagonospora nodorum isolates differing in their sensitivity to difenoconazole measured on PDA medium containing $0.05 \mu \mathrm{g} / \mathrm{ml}$ of difenozonazole. PN-18, initial isolate; PNm1, strain resistant to this sub-lethal concentration of difenoconazole ( $1^{\text {st }}$ generation). For each variant, the mean value for two experiments, each arranged in three replications, and the corresponding standard deviations are shown.

A comparison of the growth intensity of the PNm1 and PN-18 showed that the first one did not lose its difenoconazole resistance, which level did not decrease after a 
long-term cultivation on the fungicide-free medium. Even after several passages on the fungicide-free medium, PNm1 continued to grow at difenoconazole concentrations lethal for the initial natural isolate (Fig. 5) that evidences its resistance was stipulated by some genetic mutations of the initial $P$. nodorum isolate.

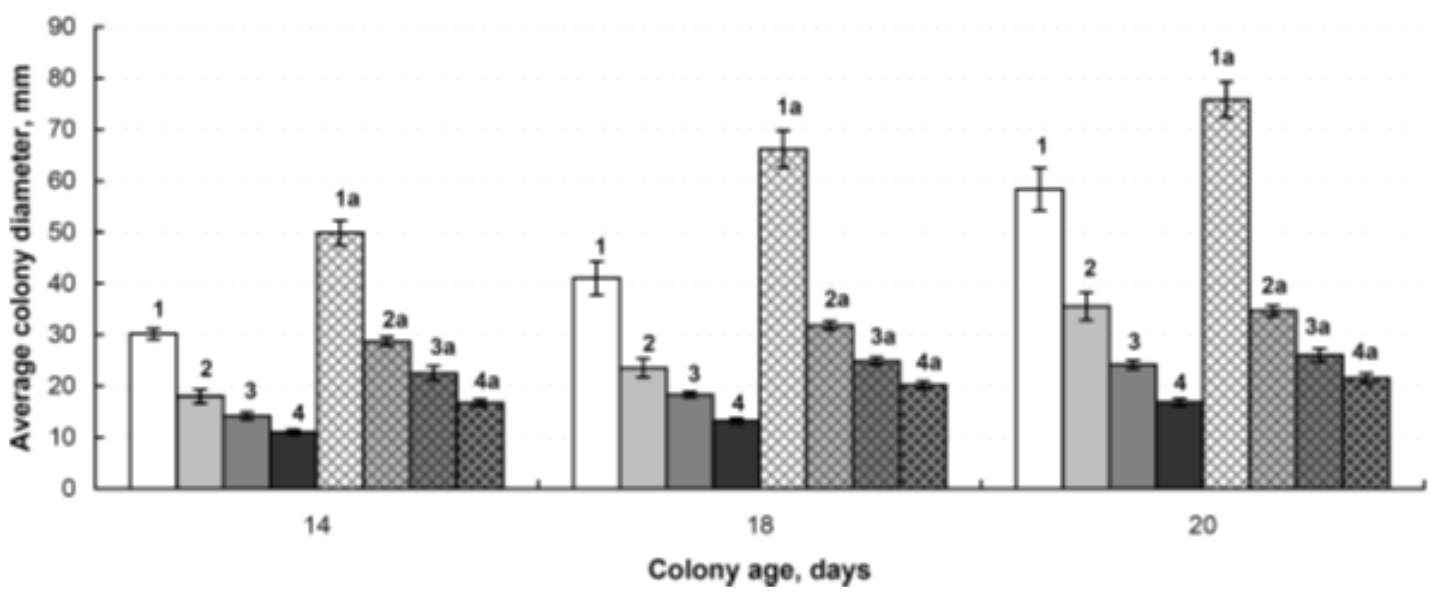

Figure 4: Dependence of the growth intensity of the initial isolate (PN-18) and resistant strain (PNm1) of $P$. nodorum grown at different concentrations of difenoconazole on the duration of cultivation. 1--4, PN-18 isolate grown at difenoconazole concentrations equal to 0.1 (1), 0.5 (2), 1.,0 (3), and 1.5 (4) $\mu \mathrm{g} / \mathrm{ml}$. 1a--4a, PNm1 strain grown at the corresponding difenoconazole concentrations. All bars are shown with the standard errors (SE).

The revealed mutant strain was also more resistant to thymol. After a two-week cultivation in the presence of this chemosensitizer, the radial growth inhibition of the initial PN-18 isolate varied from 11 to $20 \%$, whereas the mutant strain showed about twice lower growth inhibition (Table 1.

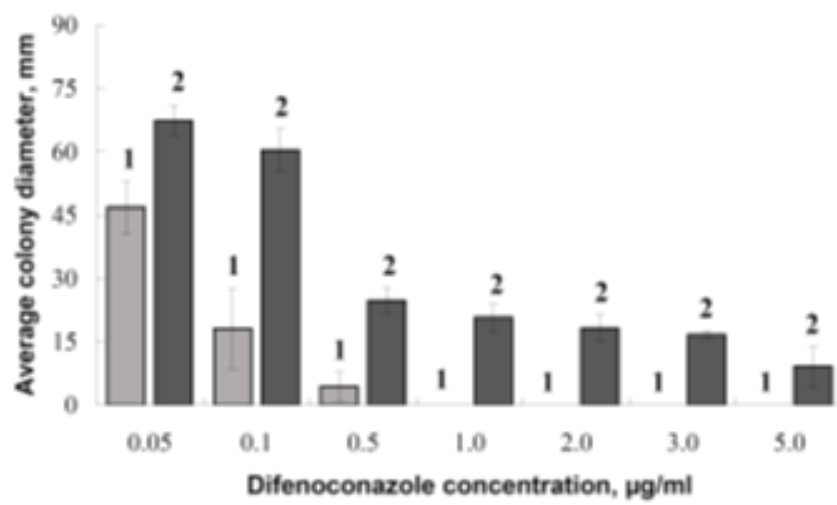

Figure 5: Development of the initial isolate (1) and mutant difenoconazole-resistant strain (2) of P. nodorum in the presence of different concentrations of difenoconazole. The bars are shown with standard errors (SE).

Co-application of the fungicide and sensitizer resulted in a statistically significant decrease of the difenoconazole resistance in the mutant strain. In the case when difenoconazole content in PDA was $0.05 \mu \mathrm{g} / \mathrm{ml}$, the presence of thymol resulted in an increase of the sensitivity of the natural mutant up to the level of the initial (non-resistant) 
TABLE 1: Decrease of the difenoconazole resistance of Parastagonospora nodorum PN-18 and PNm1 in the case of in vitro co-application of difenoconazole with thymol.

\begin{tabular}{l|c|c|}
$\begin{array}{l}\text { Compounds and their concentrations } \\
\text { in PDA, } \mu \mathrm{g} / \mathrm{ml}\end{array}$ & \multicolumn{2}{|c|}{ Colony growth inhibition, \% of the control } \\
\hline & PN-18 & PNm1 \\
\hline Thymol, 10 & $15.9 \pm 4.03$ & $6.6 \pm 0.47$ \\
\hline Difenoconazole, 0.05 & $34.0 \pm 3.25$ & $22.1 \pm 1.95$ \\
\hline Difenoconazole, 0.05 + Thymol, 10 & $42.6 \pm 2.24$ & $38.5 \pm 2.39$ \\
\hline Difenoconazole, 0.1 & $51.8 \pm 2.30$ & $33.6 \pm 0.15$ \\
\hline Difenoconazole, 0.1 + Thymol, 10 & $65.4 \pm 1.66$ & $51.9 \pm 3.58$ \\
\hline
\end{tabular}

isolate. The tendency to overcome the difenoconazole resistance was also observed in the case of the growth of a mutant strain at a higher difenoconazole concentration (Table I).

The observed growth-inhibitory effect $\left(E_{r}\right)$ of difenoconazole co-applied with thymol in relation to the resistant PNm1 strain exceeded the expected summary effect of their joint application $\left(E_{e}\right)$ calculated by the Limpel's formula. For both used difenoconazole concentrations ( 0.05 and $0.1 \mu \mathrm{g} / \mathrm{ml}$ ), $E_{r}$ values (38.5\% and $49.8 \%$, respectively) significantly $(p=0.02)$ exceeded the corresponding $E_{e}$ values ( $27.2 \%$ and $37.9 \%$, respectively). This result confirms the synergism previously revealed between these compounds [6] and suggested to enhance sensitivity of the resistant mutant to difenoconazole in the case of a fungicide co-application with thymol.

\section{Conclusion}

Difenoconazole is known to be one of triazoles belonging to so-called demethylation inhibitors (DMI fungicides), which inhibit $14-\alpha$-sterol demethylase, an enzyme involved into the ergosterol biosynthesis in fungal membranes $[16,17]$. Resistance to DMI fungicides is considered to be quantitative resulting from several mutations in the genome of plant pathogens. One of the common methods to manage such triazole resistance in agriculture is application of heightened dosages of such fungicides. Though the risk of development of resistance to these fungicides is usually assessed as medium, the appearance of fungal strains resistant to a certain DMI fungicide, as well as the development of a cross-resistance to other triazoles, have been reported for various fungi including plant pathogenic ones [18--20]. The majority of isolates from European populations of the wheat glume blotch pathogen still remain sensitive to normal levels of 
DMI fungicides [21]; at the same time, some forms possessing DMI resistance and crossresistance are periodically revealed, especially among isolates collected in the fields undergone to repeated treatment with triazoles [22]. These data show the scientists should be ready to propose environmentally safe approaches and remedies to minimize the development of DMI triazole fungicide resistance in $P$. nodorum. Results of our first attempt to improve the antifungal effect of difenoconazole by its co-application with thymol, presented in this study, allow us to suppose that at least some biogenic chemosensitizers may become one of available and efficient tools to suppress the development of DMI-resistant $P$. nodorum strains. We also plan to study the possible similar effects of other previously identified secondary metabolites of plant and microbial origin and their analogues [6], as well as to search for new effective substances, which would provide sufficient protection against triazole-resistant natural and artificially obtained $P$. nodorum mutants.

\section{Acknowledgment}

The study was financially supported by the Russian Science Foundation (project no. 18-16-00084) except for solid-phase cultivation of initial isolates on a grain substrate, which preceded the isolation of the fungicide-resistant colony sector.

\section{References}

[1] Brent, K.Y., Hollomon, D.W. (2007). Fungicide Resistance in Crop Pathogens: How can it be Managed? 2rd ed. Brussels: CropLife International. Retrieved from: http: //www.frac.info/publication/anhang/FRAC_Mono1_2007_100dpi.pdf.

[2] Campbell, B., Chan, K., Kim, J.H. (2012). Chemosensitization as a means to augment commercial antifungal agents. Front. Microbiol., vol. 3, article ID 79. DOI: 10.3389/fmicb.2012.00079.

[3] Kim, J.H., Mahoney, N., Chan, K.L., Molyneux, R.J., May, G.S., Campbell, B.C. (2008). Chemosensitization of fungal pathogens to antimicrobial agents using benzo analogs. FEMS Microbiol. Lett., vol. 281, pp. 64--72. DOI: 10.1111/j.15746968.2008.01072.x.

[4] Faria, N.C.G, Kim, J.H., Gonçalves, L.A.P., Martins, M.L., Chan, K.L., Campbell, B.C. (2011). Enhanced activity of antifungal drugs using natural phenolics against yeast strains of Candida and Cryptococcus. Lett. Appl. Microbiol., vol. 52, pp. 506--513. DOI: 10.1111/j.1472-765X.2011.03032.x. 
[5] Kim, J.H., Mahoney, N., Chan, K.L., Campbell, B.C. (2011). Antifungal activity of redox-active benzaldehydes that target cellular antioxidation. Ann. Clin. Microbiol. Antimicrob., vol. 10, article ID 23. DOI: 10.1186/1476-0711-10-23.

[6] Dzhavakhiya, V.G., Shcherbakova, L.A., Semina, Y.V., Zhemchuzhina, N.S., Campbell, B. (2012). Chemosensitization of plant pathogenic fungi to agricultural fungicides. Front. Microbiol., vol. 3, article ID 87. DOI: 10.3389/fmicb.2012.00087.

[7] Toropova, E.Yu., Kazakova, O.A., Selyuk, M.P. (2016). Monitoring of septoria blight on spring wheat in the forest-steppe of Western Siberia. Achiev. Sci. Technol. AIC, vol. 30, no. 12, pp. 33--35.

[8] Murray, G.M., Brennan, J.P. (2009). Estimating disease losses to the Australian wheat industry. Australas. Plant Pathol., vol. 38, pp. 558--570. DOI: 10.1071/AP09053.

[9] Kolomiets, T.M., Pankratova, L.F., Pakholkova, E.V. (2017). Wheat (Triticum L.) cultivars from grin collection (USA) selected for durable resistance to Septoria tritici and Stagonospora nodorum blotch. Agr. Biol., vol. 52, no. 3, pp. 561--569, DOI: 10.15389/agrobiology.2017.3.561eng

[10] Downie, R.C., Bouvet, L., Furuki, E. et al. (2018). Assessing European wheat sensitivities to Parastagonospora nodorum necrotrophic effectors and fine-mapping the Snn3-B1 locus conferring sensitivity to the effector SnTox3. Front. Plant Sci., vol. 9, article ID 881. DOI: 10.3389/fpls.2018.00881.

[11] Buzuk, A.G., Yurchenko, R.A., Buzuk, G.N. (2012). Variation of chemical composition of essential oil Thymus pulegioides L. Vestnik farmatsii, no. 1(55), pp. 19--25.

[12] Zuzarte, M., Goncalves, M.J., Cavaleiro, C et al. (2011). Chemical composition and antifungal activity of the essential oils of Lavandula viridis L'Her. J. Med. Microbiol., vol. 60, pp. 612--618. DOI: 10.1099/jmm.0.027748-0.

[13] Pakholkova, E.V., Salnikova, N.N., Kurkova, N.A., Kolomiets, T.M., Kiseleva, M.I. (2017). Pathogenic strains storage of the main causative agents of cereal crops septoriosis (leaf spot) in the State Collection of Phytopathogenic Microorganisms in All-Russian Research Institute of Phytopathology. Int. J. Pharm. Res. Allied Sci., vol. 6, pp. 120-130.

[14] Douaiher, M.N., Halama, P., Janex-Favre, M.C. (2004). The ontogeny of Stagonospora nodorum pycnidia in culture. Sydowia, vol. 56, pp. 39--50.

[15] Dzhavakhiya, V.G., Voinova, T.M., Statsyuk, N.V., Shcherbakova, L.A. (2019). Sensitization of plant pathogenic fungi to the tebuconazole-based commercial fungicide using some analogues of natural amino acids. AIP Conference Proceedings "Modern synthetic methodologies for creating drugs and functional materials", vol. 2063, article ID 030005. November 2018. DOI 10.1063/1.5087313. 
[16] Yang, C., Hamel, C., Vujanovic, V., Gan, Y. (2011). Fungicide: modes of action and possible impact on nontarget microorganisms. ISRN Ecology, vol. 2011, article ID 130289. DOI: 10.5402/2011/130289.

[17] Ziogas N.B., Malandrakis, A.A. (2015). Sterol biosynthesis inhibitors: C14 demethylation (DMIs). In: Ishii H., Hollomon D., ed. Fungicide Resistance in Plant Pathogens. Tokyo: Springer, pp. 199--216.

[18] Snelders, E., Camps, S.M., Karawajczyk, A. et al. (2012). Triazole fungicides can induce cross-resistance to medical triazoles in Aspergillus fumigatus. PloS one, vol. 7, article ID e31801. DOI: 10.1371/journal.pone.0031801.

[19] Magill, S.S., Shields, C., Sears, C.L., Choti, M., Merz, W.G. (2006). Triazole crossresistance among Candida spp.: case report, occurrence among bloodstream isolates, and implications for antifungal therapy. J. Clin. Microbiol., vol. 44, pp. 529-535. DOI: 10.1128/JCM.44.2.529-535.2006.

[20] Mavroeidi V.I., Shaw, M.W. (2005). Sensitivity distributions and cross-resistance patterns of Mycosphaerella graminicola to fluquinconazole, prochloraz and azoxystrobin over a period of 9 years. Crop Prot., vol. 24, pp. 259--266. DOI: 10.1016/j.cropro.2004.07.014.

[21] Oliver, R.P., Friesen, T.L., Faris, J.D., Solomon, P.S. (2012). Stagonospora nodorum: from pathology to genomics and host resistance. Annu. Rev. Phytopathol., vol. 50, pp. 23--43. DOI: 10.1146/annurev-phyto-081211-173019.

[22] Blixt, E., Djurle, A., Yuen, J., Olson, A. (2009). Fungicide sensitivity in Swedish isolates of Phaeosphaeria nodorum. Plant Pathol., vol. 58, pp. 655--664. DOI: 10.1111/j.13653059.2009.02041.x. 